\title{
Follow-up on short-course 2 months' rifampicin treatment of paucibacillary leprosy
}

\author{
J WARNDORFF* $\dagger$, J BOURLAND $\ddagger \&$ S R PATTYN § \\ *All Africa Leprosy and Rehabilitation Training Centre \\ (ALERT), Addis Ababa, Ethiopia; \\ $\$$ Damien Foundation, Bujumbura, Burundi; \\ $\S$ University of Antwerp and Institute of Tropical Medicine, \\ Antwerp, Belgium
}

Received for publication 11 May 1981

Summary The results of follow-up for between 1 and 3.5 years of paucibacillary leprosy patients treated with 8 weekly doses of $900 \mathrm{mg}$ rifampicin are presented.

In the pilot trial in Burundi, 8 patients were followed for 3 years and more. All did well, including 1 patient who developed a reversal reaction.

In Addis Ababa, 3 patients on rifampicin developed neuritis at 9-18 weeks after the start of therapy and were excluded from the trial. Three patients treated with rifampicin were followed for 3 years and 5 for at least 2 years. All patients had their lesions healed or considerably improved, there were no relapses and no adverse effects due to the intermittent administration of the drug. Three patients in the dapsone-treated group were followed for 3 years and 2 for at least 2 years. In this group 1 patient developed severe neuritis and 2 others, who absconded for about 2 years, did not improve clinically, or worsen.

Compared with standard dapsone therapy, rifampicin treatment did not accelerate healing; neuritis was not more frequent but it occurred much earlier. Some points to be taken care of in similar future trials are discussed.

\section{Introduction}

Dapsone treatment of paucibacillary leprosy is still of very long duration: $2-5$ years.

$\dagger$ Requests for reprints to SR Pattyn, Institute of Tropical Medicine, Nationalestraat 155, B-2000 Antwerpen, Belgium. 
Lowe $^{1}$ recommended 24 months' treatment, Wheate and Pearson ${ }^{2}$ 2-5 years, and the third and fourth WHO Expert Committees ${ }^{3,4}$ recommend that tuberculoid patients should continue treatment for 18 months after all activity has ceased and the lesions have become quiescent, which could mean a total of 24-36 months.

It is impossible to organize supervised treatment for such long periods, and it is well known that many patients who regularly show up to collect their dapsone tablets, do not necessarily take them. ${ }^{5}$

Rifampicin (RMP) is highly bactericidal for Mycobacterium leprae. ${ }^{6-9}$ In a previous study on multibacillary leprosy it was found that the morphologic index reached zero values after 2 months of weekly administration of $900 \mathrm{mg}$ rifampicin. ${ }^{10}$

Since it is estimated that paucibacillary (TT-BT) leprosy patients harbour less than $10^{6}$ bacilli, ${ }^{11}$ it was thought that it should be possible to cure such patients with a short-term treatment regimen of 8 weekly doses of $900 \mathrm{mg}$ rifampicin.

A pilot trial with this regimen was therefore undertaken in Burundi (JB) and a controlled clinical trial comparing this regimen with dapsone treatment was conducted in Addis Ababa (JW).

Preliminary results with follow-up periods of 39-64 weeks were published previously. ${ }^{12}$ We now present the results of follow-up on some of these patients for periods up to 36 months.

\section{Patients and conduct of the trials}

Patient selection and pretreatment investigations were described previously. ${ }^{12}$ Patients had to have clinical and histologically confirmed TT, BT or indeterminate leprosy, with an IB of 0 or 1 on an earlobe. In Burundi, only patients with minimal or no nerve involvement and living within acceptable walking distance of the clinics were included in the trial.

They were given $900 \mathrm{mg}$ RMP once a week under supervision during 8 weeks and thereafter dapsone placebo tablets. In Addis Ababa all patients presenting with paucibacillary leprosy were included and randomly allocated to one of the following drug regimens:

(1) Dapsone $25 \mathrm{mg} /$ day for 4 weeks, followed by $50 \mathrm{mg} /$ day for 3 years. The patients came to the treatment centre to collect their tablets. RMP placebo capsules were also given. Treatment was not supervised.

(2) RMP, $900 \mathrm{mg}$ once a week during 8 weeks under supervision, followed by dapsone placebo tablets.

In both localities, clinical and neurological examination of patients was carried out at 2 months and thereafter every 3 months for at least 3 years. 
Localization of skin lesions and results of neurological examinations were noted in especially devised files. The diameter of one or two patches were measured. Biopsy specimens were taken at the start, after 2 months and thereafter every 6 months. Patients developing reactions, severe enough to require corticosteroid therapy, were withdrawn from the trial and put on standard dapsone therapy.

\section{Results}

\section{B UR UN D I}

In Burundi, 9 patients ( 1 indeterminate, 1 TT and 7 BT) were taken in. Four patients were observed for 33-36 months, and 4 during 44 months after the start of therapy. One patient (with BT leprosy) died from an intercurrent disease unrelated to leprosy (Table 1). He had been observed for 37 weeks.

Table 1. Results of clinical observations on follow-up in patients in Burundi*

\begin{tabular}{ccll}
\hline Duration of follow-up & Number & \multicolumn{1}{c}{ Clinical status } & \\
\hline $33-36$ months & 5 & healed & 4 \\
& & $\begin{array}{l}\text { lesions diminished in number, } \\
\text { remaining ones wrinkled }\end{array}$ & 1 \\
44 months & 3 & $\begin{array}{l}\text { lesions diminished in number, } \\
\text { remaining ones wrinkled }\end{array}$ & $3 \dagger$ \\
\hline
\end{tabular}

*One patient died of intercurrent disease.

†One patient developed a reversal reaction during the first year of observation.

All patients did well: 4 were considered healed, 4 had their lesions considerably diminished in number and size. The skin lesions of patient 8 (Table 2) were erythematous and active for about 2 years. By the 36th week, she developed mild neuritis of the right radial nerve, which required no corticosteroid therapy. She had no complaints and did her hard work as a rural African woman, normally. At the follow-up examination at 44 months, the lesions had regressed and the skin at the sites of the lesions was wrinkling. One patient of this series, by the end of the rifampicin treatment developed satellite lesions around some macules, but these regressed rapidly.

During the observation period 2 patients went through 1 pregnancy and a third patient through 2 without any harm.

Biopsies of one skin lesion (Table 3) were taken approximately every 6 months. Those taken 2 years after the start of treatment still showed granulomas in all but one patient. Unfortunately, 1 set of 4 late biopsies was lost in transit. As a result, only 4 biopsies taken at 34-35 months after the start of therapy are available. Three of these were from healed or almost 
Table 2. Results of histological examination of patients in Burundi

\begin{tabular}{|c|c|c|c|c|c|}
\hline Pt No. & $\begin{array}{c}\text { Number of } \\
\text { lesions }\end{array}$ & $\begin{array}{c}\text { Start } \\
\text { treatment }\end{array}$ & After \pm 1 year & & Last examination \\
\hline 3 & 4 & 15.02 .77 & $23.03 .78 \mathrm{H}+$ & & $15.01 .80 \mathrm{H} \pm \mathrm{h}$ \\
\hline 5 & 31 & $15.02 .77(\mathrm{x})$ & $23.03 .78 \mathrm{H}+$ & $18.07 .79 \mathrm{H}+$ & $15.01 .80 \mathrm{H} \pm \mathrm{h}$ \\
\hline 6 & 34 & 20.01 .77 & $05.04 .78 \mathrm{H} \pm$ & 07.02.79 Н 0 & $07.11 .79 \mathrm{H} 0$ not $\mathrm{h}$ \\
\hline 7 & 14 & 24.03 .77 & $25.03 .78 \mathrm{H}+$ & $11.08 .78 \mathrm{H}+$ & 14.12.79 H ? almost h \\
\hline 8 & & 25.03 .77 & $\begin{array}{l}13.05 .78 \\
\text { active }\end{array}$ & $\begin{array}{l}16.02 .79 \\
\text { active }\end{array}$ & $\begin{array}{c}08.01 .80 \mathrm{H}+\begin{array}{l}\text { regression } \\
\text { wrinkled }\end{array}\end{array}$ \\
\hline 9 & 23 & 25.03 .77 & $25.03 .78 \mathrm{H}+$ & $16.02 .79 \mathrm{H}+$ & $\begin{aligned} 14.12 .79 \mathrm{H} ? & \text { lesions } \\
& \text { diminished }\end{aligned}$ \\
\hline 10 & 29 & 16.10 .77 & 06.07.78 H 0 & $06.03 .79 \mathrm{H} \pm$ & $08.01 .80 \mathrm{H} ? \mathrm{~h}$ \\
\hline 11 & 2 & 16.10 .77 & 10.07.78 H \pm & $\begin{array}{l}06.03 .79 \mathrm{H} \pm \\
1 \text { lesion }\end{array}$ & $\begin{array}{rl}08.01 .80 \mathrm{H} ? & 1 \text { lesion } \\
& \text { wrinkled }\end{array}$ \\
\hline 12 & 24 & 16.10 .77 & $10.07 .78 \pm h$ & & died \\
\hline
\end{tabular}

(x), development of satellite lesions by the end of treatment; $\mathrm{H} \pm$, discrete perivascular infiltration; $\mathrm{H}+$, histological lesions present; $\mathrm{H} 0$, histological lesions absent; $\mathrm{H}$ ?, biopsies lost; h, clinically healed. 
Table 3. Results of clinical observations on follow-up in patients in Addis Ababa

\begin{tabular}{|c|c|c|c|c|c|c|}
\hline \multirow[b]{2}{*}{$\begin{array}{l}\text { Duration of } \\
\text { follow-up } \\
\text { (months) }\end{array}$} & \multicolumn{3}{|c|}{ Dapsone treatment } & \multicolumn{3}{|c|}{ Rifampicin treatment } \\
\hline & No. & Clinical status & & No. & Clinical status & \\
\hline $14-17$ & 1 & $\begin{array}{l}1 \text { new skin lesion, loss of } \\
\text { ulnar nerve function }\end{array}$ & $: 1$ & 1 & lesions very vague & $: 1$ \\
\hline $20-25$ & 1 & lesion unchanged (a) & $: 1$ & 2 & lesions vague to very vague & $: 2$ \\
\hline $26-29$ & 2 & $\begin{array}{l}\text { lesion increased in size (b) } \\
\text { healed }\end{array}$ & $\begin{array}{l}: 1 \\
: 1\end{array}$ & 1 & wrinkled skin (c) & $: 1$ \\
\hline $30-36$ & 3 & $\begin{array}{l}\text { healed } \\
\text { fading lesions }\end{array}$ & $\begin{array}{l}: 2 \\
: 1\end{array}$ & 7 & $\begin{array}{l}\text { healed } \\
\text { very vague }(d) \\
\text { size unchanged, repigmentation }\end{array}$ & $\begin{array}{l}: 2 \\
: 3 \\
: 2\end{array}$ \\
\hline Total & 7 & & & 11 & & \\
\hline
\end{tabular}

(a) Patient absent for evaluation and drug or placebo collection during previous 22 months.

(b) Patient absent for evaluation and drug or placebo collection during previous 17 months.

(c) Patient absent for evaluation and drug or placebo collection during previous 20 months.

(d) Claimed increase of lesions at 15 months, but this was not confirmed.

healed patients, the fourth from patient 8 who developed the protracted reversal reaction. One biopsy showed no lesion, in two there was still some discrete perivascular round cell infiltrate or some very discrete patches of epithelioid cells. The biopsy of the fourth patient (patient 8, Table 2) showed tuberculoid lesions but of a smaller size as compared with previous biopsies.

\section{ADDIS ABABA}

Of the 9 previously studied patients in the DDS group, ${ }^{12} 7$ could be followed for periods between 14 and 36 months ( 2 indeterminate, 1 TT and 5 BT) (Table 3). Three of these patients did not do well: 1 patient seen at 14 months af ter the start of treatment had developed new lesions and lost his ulnar nerve function. This might be the result of the patient not taking his dapsone or being infected with dapsone resistent $M$. leprae. Two other patients seen after 24 and 28 months respectively ((a) and (b) in Table 3) had unchanged, activelooking lesions or lesions increased in size. It is remarkable that these 2 patients were the only absconders in this group: 1 patient absconded af ter 2 months and was not seen again until 24 months, the other absconded at 11 months and was not seen again until 28 months.

Of the 13 previously studied patients in the rifampicin group, 11 could be followed for periods of between 15 and 36 months (Table 3). All patients 
did well. Patient (c) in Table 3 when seen 15 months after the start of treatment claimed his lesions had increased in size, but later examinations showed the contrary and by 27 months local wrinkling of the lesions was all that was left. Patient (d) had been absent after his RMP treatment for 20 months without any harm, he has since been followed for 35 months.

Due to circumstances and frequent opposition from the patients to have biopsies these could not be taken as regularly as originally planned.

\section{Discussion}

Even long-term dapsone treatment of paucibacillary leprosy can be followed by considerable relapse rates. These depend largely on the duration of therapy, and will in the future, also on the prevalence of primary dapsone resistance.

Lowe $^{1}$ during a follow-up study of 6 months -4 years on 69 patients, observed $11.6 \%$ relapses. Seven of the 8 relapses occurred within 3-12 months af ter treatment ceased and 1 at 28 months. Three of the 7 patients had been treated for less than 1 year, 3 for between 1 and 2 years and 2 for $2-2.5$ years. Davey ${ }^{13}$ reported a relapse rate of $6 \%$, Kandaswamy ${ }^{14} 4 \%$. Ekambaram ${ }^{15}$ found a relapse rate of $1.8 \%$ in patients treated for 6 years, with $56 \%$ occurring within the first 2 years and $73.5 \%$ within the first 3 years. Later on there was a steady decline in the number of relapses. Vellut et al. ${ }^{16}$ also found that the longer the maintenance therapy was given after the lesions had become quiescent, the lower was the risk of relapses and this risk decreased steadily with time. Touw-Langendijk and $\mathrm{Naafs}^{17}$ observed $14 \%$ relapses among TT patients treated for 1.5 years, among BT patients treated for at least 5 years the relapse rate was $15 \%$ against $28 \%$ among those treated for less than 5 years. The majority of relapses occurred within 2 years.

It thus seems that follow-up periods of $2-3$ years, in trials on paucibacillary leprosy, provide most useful information.

Our original fear that it would not be possible to continue the observation of the patients participating in the present trials for a sufficiently long period of time was not realized. ${ }^{12}$ Fourteen patients out of 29 previously analysed ${ }^{12}$ have now been followed for 3 years ( 8 from Burundi and 3 from Addis Ababa on RMP, 3 from Addis Ababa on dapsone therapy), and another 7 for at least 2 years ( 5 on RMP and 2 on DDS therapy).

It is known that some patients in Addis Ababa died accidentally or moved to other parts of the country. Some patients in the rifampicin group there and in Burundi now show up very irregularly because they consider themselves healed.

Relapses in the rifampicin-treated patients were not observed. However, the confidence limits on such a small number of patients are high.

As far as could be ascertained the rifampicin-treated patients, receiving 
placebo dapsone tablets, did not take any specific drug after their 8 doses of $900 \mathrm{mg}$ rifampicin. But clearly, in future trials, provisions should be made to perform dapsone tests on urine samples.

Our previous impression at 1 year, ${ }^{12}$ that the improvement after the shortcourse 8-week intermittent rifampicin treatment of paucibacillary leprosy is not as good as after standard dapsone treatment, has not been confirmed. Patient 8 in Burundi had outspoken erythematous-active-looking lesions at the start of treatment and this situation remained unchanged for about 2 years. This could be interpreted as a reversal reaction although reversal reactions very rarely have such a long duration. One patient in Addis Ababa thought his lesions increased in size but this was not confirmed by further examinations and eventually his lesions healed. Furthermore, in Addis Ababa, 2 patients on dapsone therapy had abandoned therapy for considerable periods of time: 2 years, and showed either no improvement or worsening. In the rifampicin group, 1 patient after the end of treatment, absconded for a comparable period of time, but this did not influence his clinical evolution. These observations illustrate at their best the advantage of short-course chemotherapy, since patients could be released from control at an early stage.

Three patients in the rifampicin group in Addis Ababa developed neuritis, respectively after 9,12 and 18 weeks, ${ }^{12}$ requiring corticosteroid therapy. Later, no further cases of neuritis appeared in this group, but 1 patient in the dapsone group developed neuritis between the eighth and fourteenth month after the start of therapy. The differences in incidence of neuritis between the 2 treatment groups evidently remains statistically insignificant. But it could be that if neuritis develops in rifampicin-treated patients, it occurs at a much earlier stage. Since the development of neuritis during treatment of paucibacillary patients is in a certain way and at present unavoidable, the earlier occurrence of it under rifampicin treatment may again constitute an advantage, as patients could be instructed more precisely what to do when this complication arises.

As was expected at the start of the trial, clinical improvement in the rifampicin-treated patients continued after the administration of the drug was stopped. However, this improvement was as slow as under dapsone therapy. Particularly the skin biopsies, taken most regularly in Burundi, revealed that histological lesions remained visible for 2 years.

This is not at all surprising since symptoms in paucibacillary leprosy are mainly the result of an allergic reaction of the host to the presence of antigens of leprosy bacilli. ${ }^{18,19}$ This means that the treatment of paucibacillary leprosy should be aimed at 2 objectives: killing of the bacilli and stopping the allergic reaction. Evidently, RMP can realize the first objective rapidly and efficiently, since in the present series, no relapses were observed after 8 weekly doses of $900 \mathrm{mg}$ RMP (the second objective will have to be taken care of by other drugs). Whether this regimen can still be shortened or more intensive treatment 
regimens (daily or twice weekly or a somewhat longer treatment) would also shorten the healing phase, should be studied in future trials.

The advantages of short-course chemotherapy have been discussed elsewhere $^{20}$ and are well known from the chemotherapy of tuberculosis $\mathrm{s}^{21}$ : improved patient compliance, real possibility for supervision of treatment, lower amounts of drugs administered, lower toxicity and cost.

In this study, as in a previous one, ${ }^{10}$ when $900 \mathrm{mg}$ rifampicin once a week was administered during 3 months, no adverse effects due to intermittent rifampicin administration have been observed.

The present study has also shown that biopsies should be taken less frequently because, particularly during the early stages, they give no information and patients dislike them for they give rise to a considerable number of keloids, to which the melano-africans are so prone.

Urine samples should be tested for detection of possible additional unprescribed dapsone intake. Finally, patients developing neuritis should not be shifted to dapsone therapy but treated appropriately with corticosteroids. Whether, when this complication arises after rifampicin treatment has ended, this should be done under the cover of a bacteriostatic antileprosy drug, such as dapsone, in order to prevent relapses, remains to be studied.

\section{References}

1 Lowe J. The late results of sulphone treatment of leprosy in East Nigeria. Lepr Rev, $1954 ; 25: 113-24$.

2 Weathe HW, Pearson JMH. A practical guide to the diagnosis and treatment of leprosy in basic health unit. Addis Ababa: All African Leprosy and Rehabilitation Centre, 2nd edition, 1979.

3 WHO Expert Committee on Leprosy: Third Report, Geneva, Technical Report Series, $1966 ; 319$.

4 WHO Expert Committee on Leprosy: Fourth Report. Geneva: Technical Report Series, $1970 ; 459$.

5 Ellard GA, Gammon PT \& Harris JM. The application of urine tests to monitor the regularity of dapsone self-administration. Lepr Rev, 1974; 45: 224-34.

${ }^{6}$ Levy L, Shepard CC, Fasal P. The bactericidal effect of rifampin on M. leprae in man. a. a single dose of $600,900,1200 \mathrm{mg}$ and b. daily doses of $300 \mathrm{mg}$. Int J Lepr, 1976; 44: $183-7$.

${ }^{7}$ Pattyn SR, Saerens EJ. Minimal inhibitory dosage of rifampin in intermittent treatment of Mycobacterium leprae infection in mice. Zentralbl Bakt Hyg I Abt Orig A, 1975; 231: $503-7$.

8 Shepard CC, Levy L, Fasal P. Rapid bactericidal effect of rifampin on Mycobacterium leprae. Amer J trop Med Hyg, 1972;21:446-9.

9 Shepard CC, Levy L, Fasal P. Further experience with the rapid bactericidal effect of rifampin on Mycobacterium leprae. Amer J trop Med Hyg, 1974; 23: 1120-4.

10 Pattyn SR, Rollier MT, Rollier R, Saerens EJ, Dockx P. A controlled clinical trial on initial three months continuous and intermittent rifampicin therapy in lepromatous leprosy. Lepr Rev, 1975; 46: 129-39. 
11 Shepard CC. Rodents, Edentata and other animal models for leprosy. In: Leprosy: cultivation of the etiologic agent, immunology, animal models. Proc. of the workshop on future problems in the microbiology of $M$. leprae. Scientific Publication No. 324 PAHO, 1977.

12 Pattyn SR, Bourland J, Warndorff J, Cap A, Saerens EJ. Short course two months treatment of paucibacillary leprosy with rifampicin. Preliminary results. Ann Soc belge Méd Trop, 1979; 59: 79-85.

13 Davey TF. Discussion of the paper presented by JN Rodriguez: Relapses after sulfone therapy in leprosy of the lepromatous type. Trans. VIIth Internat. congress of Leprology, Tokyo, 1958. Tokyo: Tofu Kyokai, 1959; 241.

14 Kandaswamy V. Relapse in leprosy in a mass control scheme. Int J Lepr, 1968; 36: 657.

15 Ekambaram V. Duration of treatment for 'Disease Arrest' of non-lepromatous cases and relapse rate in these patients. Lepr Rev, 1979; 50: 297-302.

16 Vellut C, Lechat MF, Misson CB. Maintenance therapy in non lepromatous leprosy. Int J Lepr, 1979; 47: 432-3.

17 Touw-Langendijk EMJ, Naafs B. Relapses in leprosy after release from control. Lepr Rev, 1979; 50: 123-7.

18 Lowe J. The sulfone treatment of tuberculoid leprosy. Int J Lepr, 1950; 18: 457-68.

19 Turk JL, Waters MFR. Leprosy. In: Immunological Diseases, 3rd ed. Boston: Samter M, Little, Brown \& Co. 1978; 627-38.

20 Pattyn SR. The strategy of leprosy treatment. A personal view. Ann Soc belge Méd Trop, 1980; 60: 253-62.

21 Fox W, Nunn AJ. The cost of antituberculous drug regimens. Amer Rev Resp Dis, 1979; 120: 503-9. 